\title{
Prevalence of germline TP53 variants among early-onset breast cancer patients from Polish population
}

\author{
Emilia Rogoża-Janiszewska ${ }^{1}$ (D) Karolina Malińska ${ }^{1} \cdot$ Bohdan Górski $^{1} \cdot$ Rodney J. Scott $^{2,3} \cdot$ Cezary Cybulski $^{1}$. \\ Wojciech Kluźniak ${ }^{1}$ - Marcin Lener ${ }^{1}$ - Anna Jakubowska ${ }^{1}$ - Jacek Gronwald ${ }^{1} \cdot$ Tomasz Huzarski $^{1}$. Jan Lubiński ${ }^{1}$. \\ Tadeusz Dębniak ${ }^{1}$
}

Received: 25 April 2020 / Accepted: 20 August 2020 / Published online: 4 September 2020

(c) The Author(s) 2020

\begin{abstract}
Background The objective of this study was to determine spectrum and prevalence of germline mutations in TP53 gene among Polish women with early-onset breast cancer (BC), which has not been determined until now.

Methods A cohort of 100 females with $\mathrm{BC}$ diagnosed $\leq 30$ years of age and with a positive family history of cancer was used as a discovery cohort. 1880 women with $\mathrm{BC} \leq 45$ years old and a control group of 2000 healthy women were genotyped as a replication phase of this study.

Results Four heterozygous pathogenic missense mutations were detected in a group of 100 patients with early-onset breast cancer. On the basis of software prediction and available literature data, all these variants were defined as pathogenic. None of these TP53 variants were detected among 1880 breast cancer patients and 2000 healthy controls. No large mutations were found among early-onset cases using MLPA reaction.

Conclusion Germline pathogenic TP53 variants were found in 4\% early-onset Polish BC patients. No founder mutations were identified in Polish population. To improve the treatment and surveillance screening, the search for germline TP53 pathogenic variants is recommended for all female $\mathrm{BC}$ cases diagnosed $\leq 30$ years old.
\end{abstract}

Keywords TP53 $\cdot$ Early-onset breast $\cdot$ Cancer $\cdot$ Li-fraumeni $\cdot$ Mutation

\section{Introduction}

Breast cancer is the most frequent cancer, affecting 2.1 million women annually, and causes the greatest number of cancer-related deaths among women. In 2018, it was estimated that 627,000 women died from breast cancer-which equates to approximately $15 \%$ of all cancer deaths among

Electronic supplementary material The online version of this article (https://doi.org/10.1007/s12282-020-01151-7) contains supplementary material, which is available to authorized users.

Emilia Rogoża-Janiszewska

emilia.rogoza@pum.edu.pl

1 Department of Genetics and Pathology, International Hereditary Cancer Center, Pomeranian Medical University, Szczecin, Poland

2 School of Biomedical Sciences and Pharmacy, University of Newcastle, Newcastle, NSW, Australia

3 Department of Molecular Medicine, NSW Health Pathology-Hunter, Newcastle, NSW, Australia women. Breast cancer incidence is higher among women in more developed regions, and increasing in nearly every region globally [1].

In Poland, breast cancer accounts for about 23\% (18,615 cases) of 81,620 cases of malignant neoplasms in women annually. The incidence among premenopausal women (20-49 years) has increased by approximately 1.7 times over the past three decades. In 2016, 103 cases of breast cancer were reported in women who are 29 years old or younger, and 401 cases diagnosed in women who are 34 years of age or younger [2].

The molecular basis of the vast majority of early-onset $\mathrm{BC}$ cases remains unknown. BRCA mutations accounts for $10-20 \%$ of women with early-onset breast cancer (defined as breast cancer diagnosed under age 40 years) [3]. Mutations in other breast cancer susceptibility genes such as $C D H 1$, PTEN, STK11, CHEK2, PALB2 and others, may explain up to $4 \%$ of early-onset cases [4].

TP53 pathogenic germline variants are observed in a high percentage of cancers diagnosed at a young age and 
correlate with an unfavorable prognosis. $\mathrm{BC}$ associated with pathogenic germline TP53 is the most frequent neoplasm among female TP53 mutation carriers (25.5\% of all tumors and $80 \%$ of all cancers in the 16-45 year-age women group $[5,6]$. TP53 gene mutations are present in up to $5-7 \%$ of all early-onset $\mathrm{BC}$ cases diagnosed under 30 years and in $2-6 \%$ of BC patients younger than 35 [7, 8]. The incidence of de novo mutations in TP53 is somewhere between 7 and 20\% [9]. Inherited TP53 gene mutations increase the risk of numerous cancer types, including breast cancer, leukemia, sarcomas, central nervous system (CNS) tumors, and adrenal cortical cancer [as part of Li-Fraumeni syndrome (LFS)] [10]. The most frequent cancer types observed in carriers of TP53 pathogenic variants were breast cancer (24-31.2\%), soft tissue and bone sarcoma (11.6-17.8\%), followed by adrenocortical carcinoma (6.5-9.9\%), and brain tumors ( $3.5-14 \%$ ) [7, 10-13]. TP53 (tumor protein 53 gene) is a tumor suppressor, which controls growth and cell division. It protects cells against genome changes resulting from DNA damage by suppressing proliferation or activating apoptosis [14]. The most common mutations in the total spectrum of changes in the TP53 gene are point missense mutations (75\%), that involve the DNA segment encompassing exons $5-8[15,16]$. This segment determines the biological activity of the protein. Other germline variants observed in TP53 are frameshift insertions and deletions (9\%), nonsense (7\%) and silent mutations (5\%) [17]. However, internationally, the incidence of large mutations in TP53 is estimated to be around 10\% [17-19]. People with a heterozygous germline variant in TP53 have a 50\% risk of developing cancer under 31 years of age and almost $100 \%$ risk of developing a malignancy before 70 years of age [20].

The objective of this study was to determine the spectrum and prevalence of germline pathogenic variants in TP53 among Polish women diagnosed with early-onset BC, which has not previously been assessed in the Polish population.

\section{Patients and methods}

\section{Study groups}

Two non-overlapping groups of patients with breast cancer were examined for this study:

- A cohort of 100 unrelated patients diagnosed with earlyonset breast cancer $\leq 30$ years of age (range of 16-30 years; mean 26 years) was used as a discovery cohort to detect germline TP53 variants. All patients had a positive family history of cancer: 72 of these 100 families fulfilled the LFS Chompret criteria, with the occurrence of breast cancer among first or second-degree relatives of a proband affected with early-onset BC. The remaining 28 of these
100 families were characterized by the occurrence of another tumors (colorectal, gastric, prostate, ovarian, pancreas, melanoma), which are not found in the spectrum of cancer characteristic of classical LFS among first or second-degree relatives of the early-onset patients.

The patients were selected from a registry of 25,000 breast cancer cases housed at the Hereditary Cancer Center in Szczecin: out of 448 based on the age of onset of breast cancer ( $\leq 30$ years), out of 388 early-onset cases tested negative for a pathogenic variants in BRCA1 or BRCA2.

- A cohort of 1880 patients with breast cancer diagnosed $\leq 45$ years of age (range 19-45 years; mean 39 years), who were diagnosed between 2008 and 2013 at 18 different hospitals in Poland. All patients diagnosed with invasive breast cancer at participating centers were eligible to participate and were unselected for family history. The patient participation rate was $76.1 \%$. Patients from this group were also selected with respect to a negative result for screening tests for gene predisposing to a high risk of developing breast cancer-BRCA1/2(-). These patients were used as a replication cohort that allowed the estimation of the frequency of pathogenic variants detected at an earlier stage using TaqMan assays.

Clinicopathological features of the cases are presented in Table 1.

\section{Controls}

The control group consisted of 2000 healthy women (age range of 20-100; mean age of 53).

The healthy adults were deemed as having a negative cancer family history (first- and second-degree relatives included). These women were diagnosed in Szczecin between 1996 and 2004 and were part of a population-based study of the 1.5 million residents of West Pomerania (northwest Poland) to identify familial aggregations of malignancies among first and second-degree relatives from 1.258 million residents (87\%) who were registered with the West Pomeranian Regional Health Foundation. The patient participation rates exceeded $75 \%$.

During the interview, the goals of the study were explained, informed consent was obtained, genetic counseling was given and a blood sample taken for DNA analysis. All patients and control subjects are of European ancestry and ethnic Poles.

\section{Methods}

\section{Discovery phase}

DNA was isolated from blood taken from the 100 participants $\leq 30$ years of age using standard methods. Peripheral 
Table 1 Clinicopathological features of BC patients

\begin{tabular}{|c|c|c|}
\hline Characteristics & $\begin{array}{l}\text { Discovery cohort } \\
(n=100)\end{array}$ & $\begin{array}{l}\text { Valida- } \\
\text { tion cohort } \\
(n=1880)\end{array}$ \\
\hline \multicolumn{3}{|l|}{ Age at diagnosis } \\
\hline-20 & $5(5 \%)$ & $1(0.05 \%)$ \\
\hline $21-30$ & $95(95 \%)$ & $111(5.9 \%)$ \\
\hline $31-40$ & & $804(42.7 \%)$ \\
\hline $41-50$ & & $964(51.3 \%)$ \\
\hline \multicolumn{3}{|l|}{ Sex } \\
\hline Female & $100(100 \%)$ & $1880(100 \%)$ \\
\hline Male & 0 & 0 \\
\hline \multicolumn{3}{|l|}{ Race } \\
\hline White (Slavic) population) & $100(100 \%)$ & $1880(100 \%)$ \\
\hline \multicolumn{3}{|l|}{ Hormone receptor status } \\
\hline ER & $33(33 \%)$ & $695(37 \%)$ \\
\hline $\mathrm{PgR}$ & $28(28 \%)$ & $752(40 \%)$ \\
\hline HER2 & $21(21 \%)$ & $211(11.2 \%)$ \\
\hline Triple negative & $9(9 \%)$ & $162(8.6 \%)$ \\
\hline Unknown & $9(9 \%)$ & $60(3.2 \%)$ \\
\hline \multicolumn{3}{|l|}{ Status } \\
\hline Alive & $88(88 \%)$ & $1710(91 \%)$ \\
\hline Dead & $12(12 \%)$ & $170(9 \%)$ \\
\hline \multicolumn{3}{|l|}{ Histopathological type } \\
\hline Ductal carcinoma & $54(54 \%)$ & $950(50.5 \%)$ \\
\hline Lobular carcinoma & $4(4 \%)$ & $105(5.6 \%)$ \\
\hline Medullary carcinoma & $3(3 \%)$ & $77(4.1 \%)$ \\
\hline DCIS & $2(2 \%)$ & $55(2.9 \%)$ \\
\hline Others & $10(10 \%)$ & $130(6.9 \%)$ \\
\hline Unknown & $27(27 \%)$ & $563(29.9 \%)$ \\
\hline
\end{tabular}

blood leukocytes were isolated and subsequent DNA extraction was undertaken in the Department of Genetics and Pathology in Szczecin. To identify germline mutations in the TP53, Sanger sequencing was performed and MLPA was used to screen for larger insertions or deletions.

\section{Sanger sequencing}

All protein coding fragments of TP53 (exons 2-11) were examined by the Sanger sequencing. The sequences of the primers are presented in electronic supplementary material (Supplementary Table 1). The sequencing reaction was performed using a BigDye Terminator v3.1 Cycle Sequencing Kit (Life Technologies). Sequencing products were analysed using a genetic analyzer ABI Prism 3500XL (Life Technologies). All TP53 sequences were compared to the NCBI reference sequence (RefSeq) reported in GenBank: NM_000546.5. The complete region of TP53 gene was amplified and sequenced in both forward and reverse directions. If a pathogenic mutation was detected, the
DNA sample from a second patient was resequenced for confirmation.

\section{Multiplex ligation-dependent probe amplification (MLPA)}

MLPA reaction was undertaken using the SALSA MLPA kit P056 (MRC Holland, Amsterdam, The Netherlands). MLPA is used for study on both hereditary disorders and tumours.

\section{In silico prediction models}

All detected variants were checked in appropriate databases and algorithms to assess their potential pathogenicity. Gene variants were submitted to the following in silico prediction models:

- Mutation taster-that includes all publicly available single-nucleotide polymorphisms (SNPs) and indels from the 1000 Genomes Project2 as well as known disease variants from ClinVar3 and HGMD Public4. Test results are the evaluated by a naive Bayes classifier2, which predicts the disease potential [21].

- ClinVar-ClinVar processes submissions reporting variants found in patient samples, assertions made regarding their clinical significance, information about the submitter, and other supporting data. The alleles described in submissions are mapped to reference sequences, and reported according to the HGVS standard [22].

- PROVEAN (protein variation effect analyzer) - predicts whether an amino acid substitution or indel has an impact on the biological function of a protein [23].

- PolyPhen-2(polymorphism phenotyping v2)—automatic tool for prediction of possible impact of an amino acid substitution on the structure and function of a human protein [24].

- Align-GVGD-The program allows you to analyze your own protein sequence (in FASTA format), or choose from our small but growing library of matches [25].

- IARC TP53 Database-compiles various types of data and information on human TP53 gene variations related to cancer. Data are compiled from the peer-reviewed literature and from generalist databases [17].

\section{Association phase}

Changes that showed the strongest functional relationship with tumor pathogenesis (analysis used algorithms and databases) were selected for verification in the second stage of the project-association studies. These studies were carried out using real-time PCR. 


\section{Real-time PCR}

The TP53 variants detected during discovery phase were genotyped using a TaqMan assay (Applied Biosystems/Life Technologies) and the LightCycler Real-Time PCR 480 system (Roche Life Science). The primer and probe sequences were avaiable upon request. Laboratory technicians were blinded to case-control status. The overall genotyping call rate was $99.3 \%$.

\section{Statistical analysis}

All genotype comparisons between cases and controls were performed using Chi-square test. OR value was calculated for each comparison together with their $95 \%$ CI.

\section{Results}

Four heterozygous pathogenic germline mutations were detected in a group of 100 patients with early-onset breast cancer: (1) c.844C > T (p.Arg282Trp, rs28934574), (2) c.818G > A (p.Arg273His, rs28934576), (3) c.733G > A (p.Gly245Ser, rs28934575), (4) c.659A > G (p.Tyr220Cys, rs121912666). On the basis of available literature data, informations in databases and in silico analysis revealed these variants to be "missense" variants defined as pathogenic/likely pathogenic. One recurrent common missense variant- c. 215C > G (p.Pro72Arg, rs 1042522) was also identified (Table 2). Additionally, four synonymous, three 5'UTR and twelve intronic alterations were found (Table 3).

$T P 53$ c.844C $>T$ ( $r$ 228934574) was localized in exon 8 . This variant converts the amino acid arginine (CGG) to tryptophan (TGG) in codon 282-p. Arg282Trp. 844C $>$ T, was initially reported as a founder mutation in the FrenchCanadian population [26]. The IARC database describes this germline mutation in 65 cases [17]. According to the databases, the incidence of this variant among the European population is $1 / 135368$ Europeans (0.00001) [27]. It was found that the change in $\mathrm{R} 282 \mathrm{~W}$ is associated with a much earlier age of onset of the first tumor [28]. The patient in whom it was detected developed breast cancer $[\operatorname{ER}(+)$, PR(-), HER2 (3+)] at the age of 22 during pregnancy was diagnosed. The proband's mother had $\mathrm{BC}$ at the age of 37 [ER(-), PR(-), HER2(3+)]. Family history of the proband was presented on Fig. 1.

TP53 c.818G >A (rs28934576) was detected in exon 8 . This change causes the conversion of the amino acid arginine (CGT) to histidine (CAT) in codon 273-p. Arg273His. The patient in whom this change was identified developed breast cancer at the age of 27 years $[\operatorname{ER}(-), \operatorname{PR}(-)$, HER $2(3+)$ ]. The c. $818 \mathrm{G}>\mathrm{A}$ variant is the second most commonly reported mutation in the TP53 gene in the COSMIC database [29]. The incidence of this variant among the European population is 1/1006 (0.001) Europeans [27]. The IARC database describes this germline mutation in $97 \mathrm{car}-$ riers [23]. The family history of the proband was presented on Fig. 2.

TP53 c.733G >A (rs28934575) identified in exon 7, converts the amino acid glycine (GGC) to serine (AGC) in codon $245-$ p. Gly245Ser. The patient with TP53 c. $733 \mathrm{G}>\mathrm{A}$ change was diagnosed at the age of 26 years with ductal breast cancer [ER(-), PR(-), HER2(3+)].

The incidence of this variant in the general population is 1/125 568 (0.00001) [27]. The IARC database describes this germline variant in 77 cases [17]. The family history of the proband was presented in Fig. 3.

TP53 c. 659A > G (rs 121912666) is located in exon 6. This missense mutation converts the amino acid tyrosine (TAT) to cysteine (TCT) in codon 220 of the TP53 protein-p.Tyr220Cys. TP53 c. 659A $>$ G occurs in families with the LFS phenotype. At the age of 22 , the carrier was diagnosed with ductal BC; 2 years later, she developed chondrosarcoma on the right scapula, histological

Table 2 Missense TP53 mutations detected in Polish early-onset BC patients

\begin{tabular}{|c|c|c|c|c|c|c|c|c|}
\hline Location & SNP & Cons e que nce & $\begin{array}{l}\text { IARC TP53 } \\
\text { Databas e (TA } \\
\text { Clas s) }\end{array}$ & $\begin{array}{l}\text { Mutation Tas } \\
\text { te } r\end{array}$ & ClinVar & PROVEAN & PolyPhe n-2 & AGVGD \\
\hline c. $844 \mathrm{C}>\mathrm{T}$ & rs28934574 & p.Arg282Trp & Non-functional & $\begin{array}{l}\text { Prediction dis- } \\
\text { ease causing }\end{array}$ & Pathogenic & $\begin{array}{l}-7.65 \text { Deleteri- } \\
\text { ous }\end{array}$ & $\begin{array}{c}\text { 1.0 Probably } \\
\text { damaging }\end{array}$ & Class C65 \\
\hline c. $818 \mathrm{G}>\mathrm{A}$ & rs28934576 & p.Arg273His & Non-functional & $\begin{array}{l}\text { Prediction dis- } \\
\text { ease causing }\end{array}$ & $\begin{array}{l}\text { Pathogenic/ } \\
\text { likely patho- } \\
\text { genic }\end{array}$ & $\begin{array}{l}-4.775 \text { Delete- } \\
\text { rious }\end{array}$ & $\begin{array}{l}\text { 0.999 Probably } \\
\text { damaging }\end{array}$ & Class C25 \\
\hline c. $733 \mathrm{G}>\mathrm{A}$ & rs28934575 & p.Gly245Ser & Non-functional & $\begin{array}{l}\text { Prediction dis- } \\
\text { ease causing }\end{array}$ & Pathogenic & $\begin{array}{l}-5.877 \text { Delete- } \\
\text { rious }\end{array}$ & $\begin{array}{l}\text { 0.998 Probably } \\
\text { damaging }\end{array}$ & Class C55 \\
\hline c. $659 \mathrm{~A}>\mathrm{G}$ & rs 121912666 & p.Tyr220Cys & Non-functional & $\begin{array}{l}\text { Prediction dis- } \\
\text { ease causing }\end{array}$ & Pathogenic & $\begin{array}{l}-8.592 \text { Delete- } \\
\text { rious }\end{array}$ & $\begin{array}{l}\text { 0.949 Probably } \\
\text { damaging }\end{array}$ & Class C65 \\
\hline c. $215 \mathrm{C}>\mathrm{G}$ & rs1042522 & p.Pro72Arg & Not available & $\begin{array}{l}\text { Prediction poly- } \\
\text { morphism }\end{array}$ & Benign & - 0.186 Neutral & 0.217 Benign & Class C0 \\
\hline
\end{tabular}


Table 3 TP53 non-pathogenic variations identified in Polish early-onset breast cancers

\begin{tabular}{|c|c|c|c|c|c|}
\hline Variant & Exon/Intron & Amino acid & rs number & Effect & $\begin{array}{l}\text { Number } \\
\text { of cases }\end{array}$ \\
\hline c. $74+38 \mathrm{C}>\mathrm{G}$ & Intron 2 & - & rs1642785 & 5'UTR variant & 18 \\
\hline c. $75-40 \mathrm{G}>\mathrm{A}$ & Intron 2 & - & rs 372756865 & 5'UTR variant & 1 \\
\hline c. $75-48 \mathrm{~T}>\mathrm{C}$ & Intron 2 & - & rs1295353442 & 5'UTR variant & 5 \\
\hline c. $97-29 \mathrm{C}>\mathrm{A}$ & Intron 3 & - & rs 17883323 & Intronic & 2 \\
\hline $\begin{array}{r}\text { c. } 96+25 \text { ACCTGG } \\
\text { AGGGCTGGGG }\end{array}$ & Intron 3 & - & rs59758982 & Intronic & 26 \\
\hline c. $97-29 \mathrm{C}>\mathrm{A}$ & Intron 3 & - & rs 17883323 & Intronic & 2 \\
\hline c. $560-40 \mathrm{~A}>\mathrm{G}$ & Intron 5 & - & rs377059569 & Intronic & 1 \\
\hline c. $618 \mathrm{G}>\mathrm{A}$ & Exon 6 & p.Leu206= & rs 142813240 & Synonymous & 3 \\
\hline c. $639 \mathrm{~A}>\mathrm{G}$ & Exon 6 & p. $\operatorname{Arg} 213=$ & rs $1,800,372$ & Synonymous & 1 \\
\hline c. $672+62 A>G$ & Intron 6 & - & rs1625895 & Intronic & 7 \\
\hline c. $782+72 \mathrm{C}>\mathrm{T}$ & Intron 7 & - & rs 12947788 & Intronic & 8 \\
\hline c. $782+92 \mathrm{~T}>\mathrm{G}$ & Intron 7 & - & rs $12,951,053$ & Intronic & 8 \\
\hline TP53_g.14032G > A & Exon 9 & p. Lys $320=$ & - & Synonymous & 2 \\
\hline c. $993+12 \mathrm{~T}>\mathrm{C}$ & Intron 9 & - & rs1800899 & Intronic & 1 \\
\hline $17: 7673445 \mathrm{G}>\mathrm{T}$ & Intron 9 & - & - & Intronic & 1 \\
\hline c. $1077 \mathrm{~A}>\mathrm{G}$ & Exon 10 & p. $\operatorname{Pro} 359=$ & rs539224556 & Synonymous & 1 \\
\hline c. $1100+44 C>T$ & Intron 10 & - & rs 905346274 & Intronic & 1 \\
\hline c. $1100+30 \mathrm{~A}>\mathrm{T}$ & Intron 10 & - & rs 17880847 & Intronic & 3 \\
\hline c. $1101-49 \mathrm{C}>\mathrm{T}$ & Intron 10 & - & rs 17881850 & Intronic & 3 \\
\hline
\end{tabular}

I

II

III
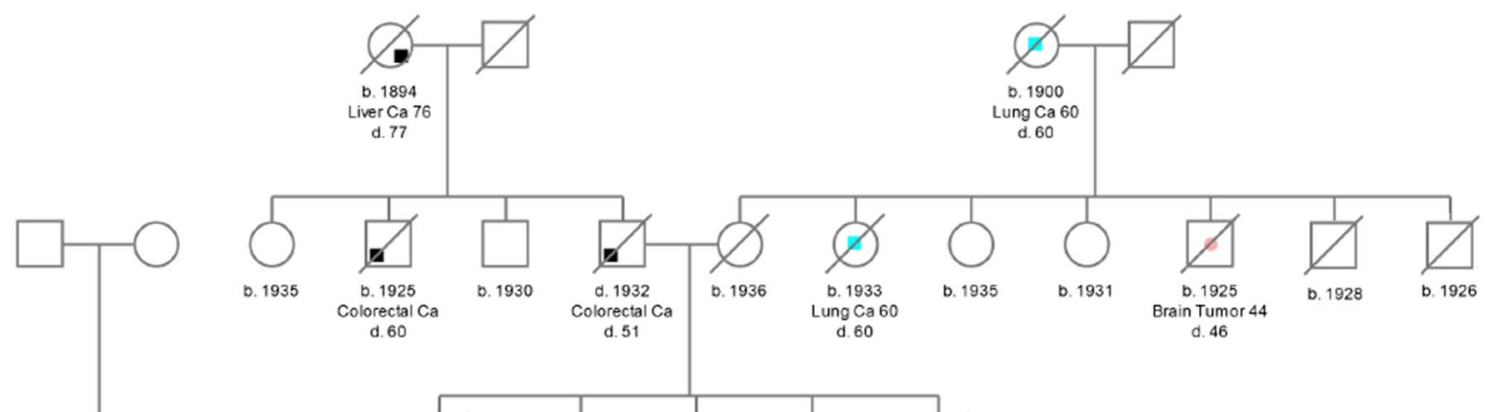

IV

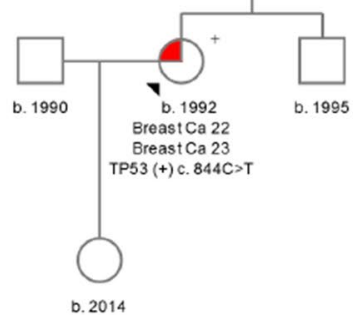

Fig. 1 Pedigree of the family with c.844C $>$ T detected variant. (+) mutation positive, (-) mutation negative

grade $\mathrm{G} 2$, and at the age of 26 , a ductal $\mathrm{BC}[\mathrm{ER}(+)$, $\operatorname{PR}(-)$, HER2 $(1+)]$. The patient died at the age of 27. The incidence of this variant among the European population is 1/135 358 (0.00001) Europeans [27]. The IARC database describes this variant among 50 individual carriers [17]. The family history of the proband was presented on Fig. 4. 


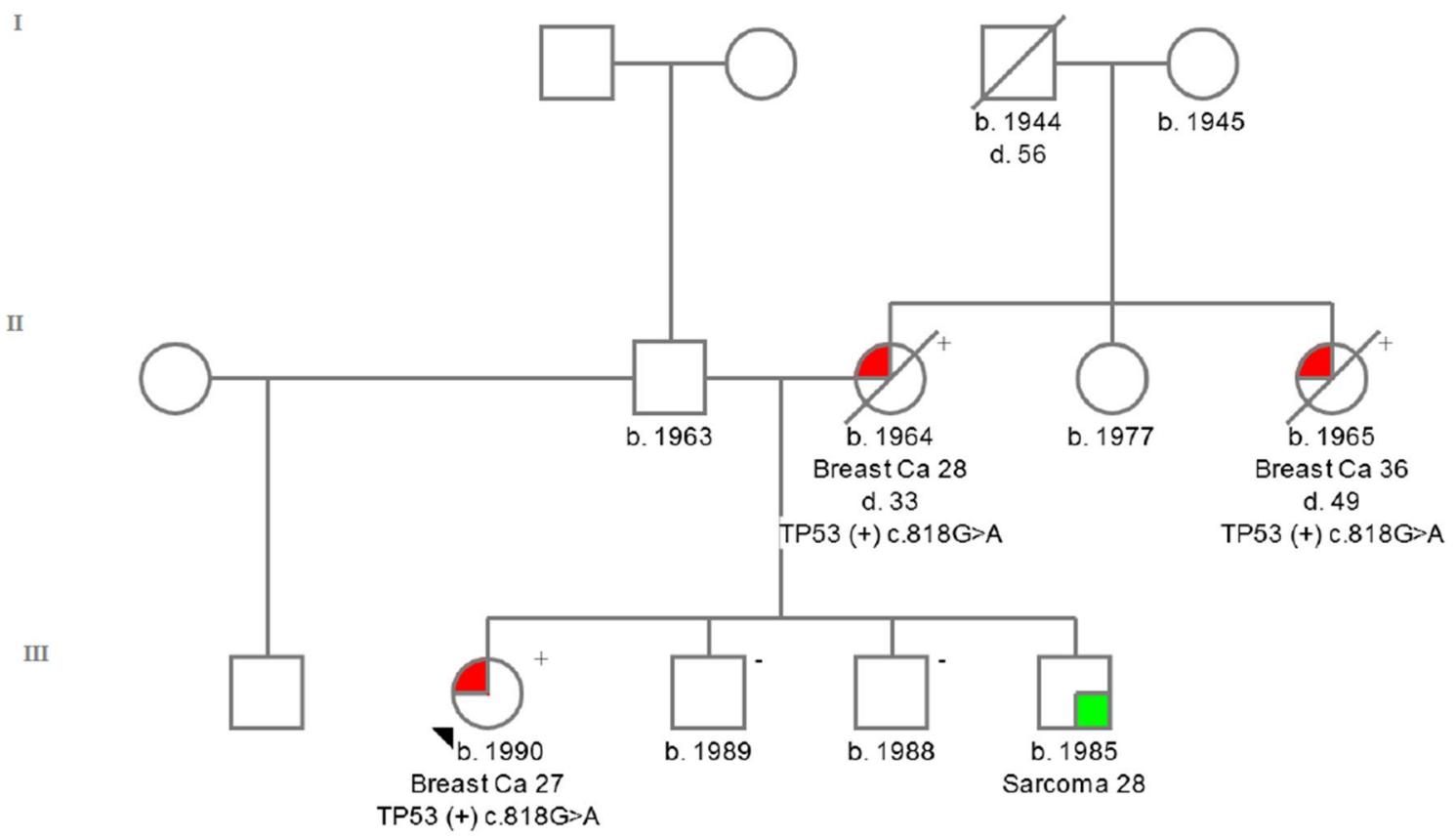

Fig. 2 Pedigree of the family with c.818G $>$ A detected variant. (+) mutation positive, (-) mutation negative

I

II

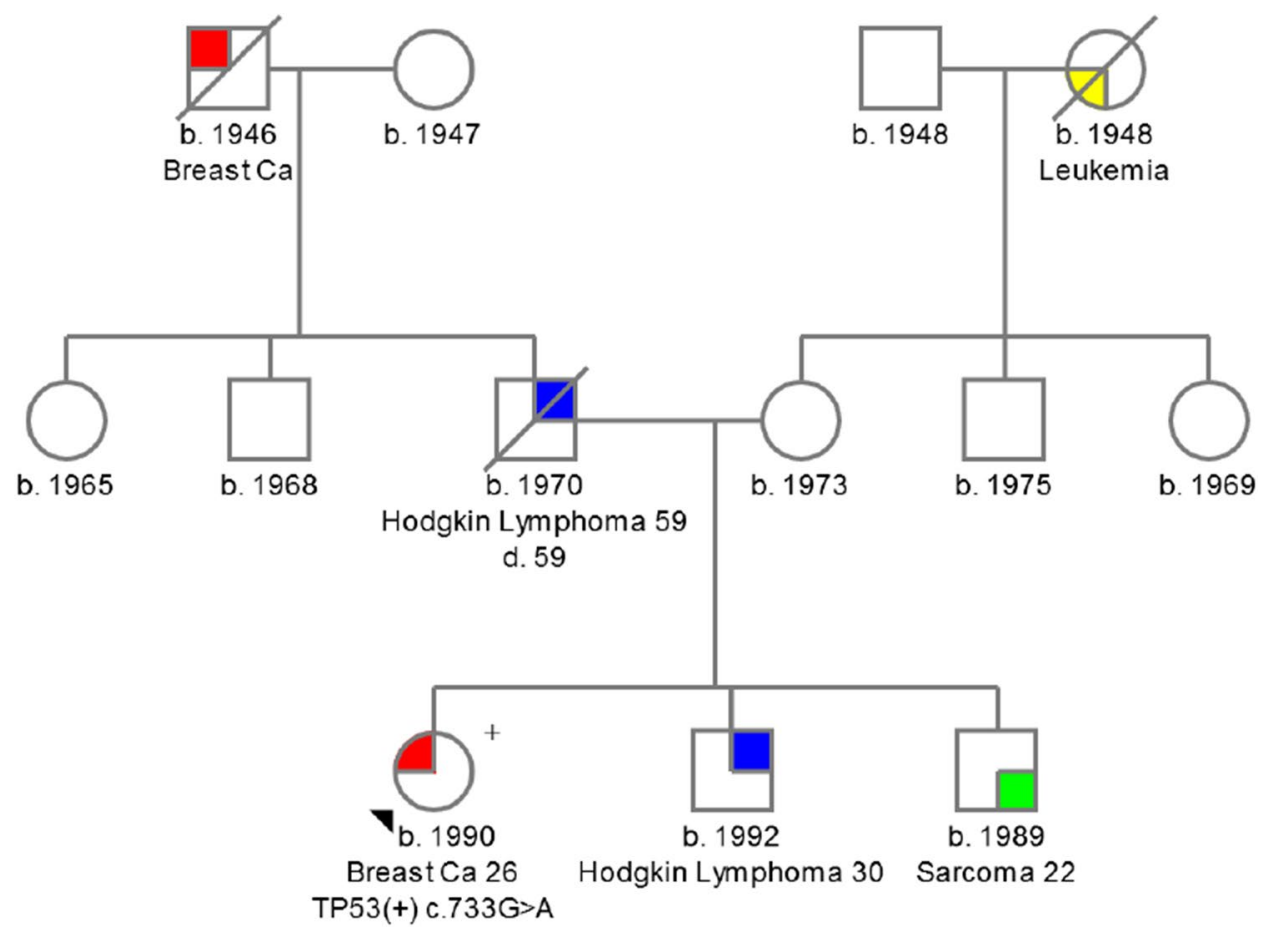

Fig. 3 Pedigree of the family with c.733G > A detected variant. (+) mutation positive, (-) mutation negative

\section{Large mutations}

No DNA alterations were detected among the 100 earlyonset BC patients using MLPA reaction.

\section{TaqMan analysis}

None of TP53 variants (c.818G $>$ A, c. $733 \mathrm{G}>\mathrm{A}$, c. $659 \mathrm{~A}>\mathrm{G}, \mathrm{c} .844 \mathrm{C}>\mathrm{T}$ ) were detected among 1880 breast cancer patients or the 2000 healthy controls. The TP53 


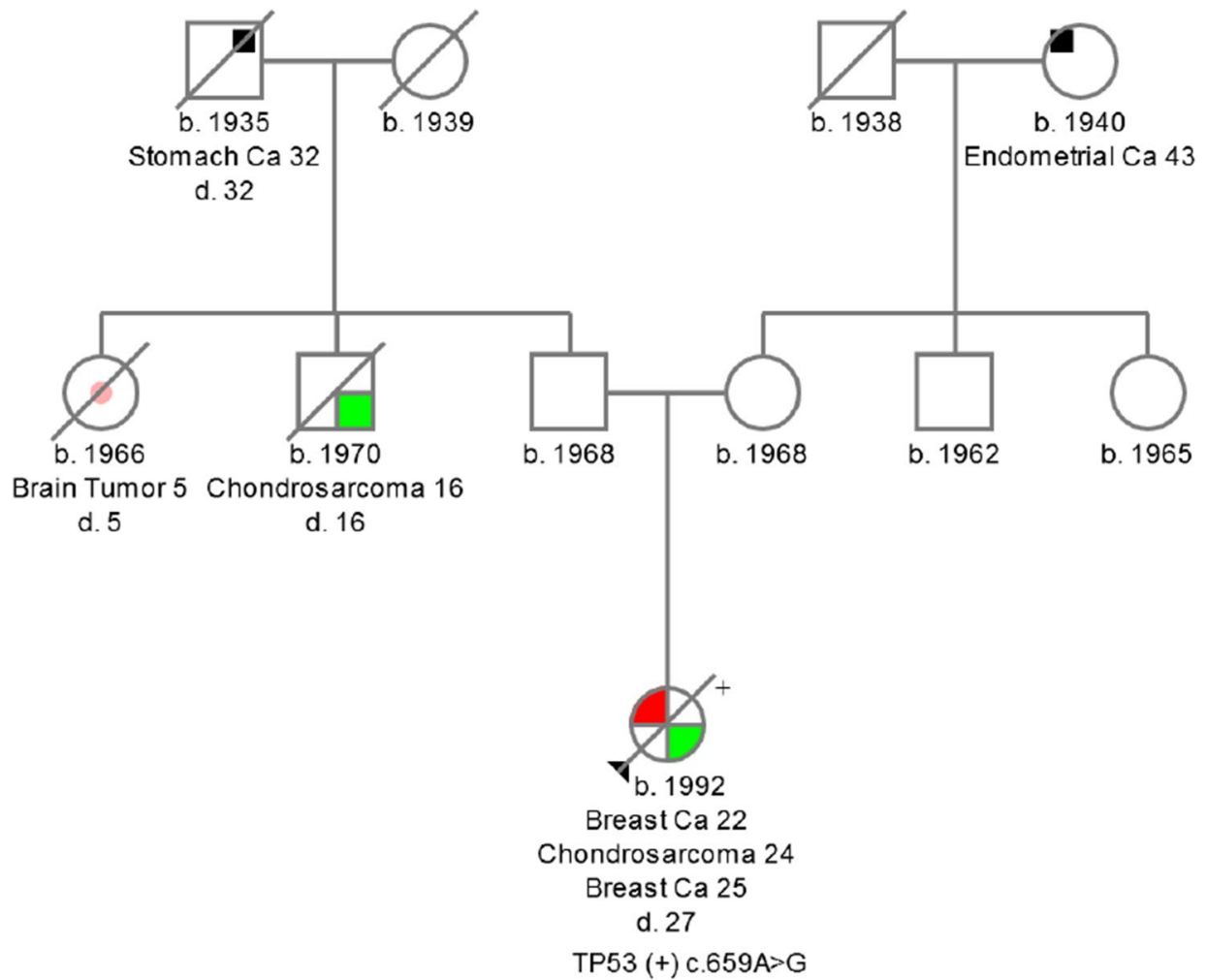

Fig. 4 Pedigree of the family with c.659A $>$ G detected variant. (+) mutation positive, $(-)$ mutation negative

c. $844 \mathrm{C}>\mathrm{T}$ variant was detected in 1 out of $1880 \mathrm{BC}$ cases. However, after genetic counselling, it turned out that this patient is a first degree relative of a proband (Fig. 1).

A non-pathogenic missense variant c. $215 \mathrm{C}>\mathrm{G}$ was detected in 747 out of $1880 \mathrm{BC}$ cases $(39.7 \%)$ and 797 out of 2000 controls $(39.8 \%)$. The difference in allele frequency was not statistically significant (OR -0.995 ; $p$-value $-0.967)$

\section{Discussion}

The aim of this study was to determine the spectrum and prevalence of germline pathogenic variants in TP53 among early-onset breast cancer patients from the Polish population. We found that germline TP53 pathogenic variants can be found in $4 \%$ of Polish early-onset BC patients with a positive cancer family history. None of these four variants appeared to be recurrent. No large insertions or deletions were found and thus are extremely rare. Only one of the four families meets classical LFS criteria. Our research confirmed the frequency of pathogenic variants in TP53 as determined by others. All detected variants were missense mutations and have previously been described in other reports [30-32].

In The Netherlands, Bakhuizen et al. [33] revealed in 370 women diagnosed with $\mathrm{BC}<30$ years of age not carrying any deleterious variants in BRCA1/2 eight (2.2\%) TP53 germline pathogenic variants. In women without a family history suggestive of LFS or a personal history of multiple LFS-related tumors, the TP53 pathogenic variant frequency was $<1 \%$. In the Mexican population, five pathogenic variants $(9.4 \%)$ were found in women with invasive ductal and lobular carcinomas, younger than 36 years of age and BRCA1/2 negative. All patients had a familial history suggestive of LFS. One of the variants (c.844C $>$ T) was initially reported as a founder mutation in the French-Canadian population [34] and was detected in our study. Among 2 out of 133 Taiwanese patients (median age-44) were found to carry the germline pathogenic variant p.G245S and p.R248Q in TP53, which results in the defective function of TP53. 94 out of 133 patients had positive family history of cancer. The mutation p.G245S was also detected in our study. Both patients with a TP53 mutation were diagnosed as LiFraumeni syndrome [30].

Rashid M.U. et al. assessed the prevalence of TP53 variants in 105 early-onset BC patients from Pakistan (negative for $B R C A 1 / 2$ pathogenic variants). The study group included 67 women diagnosed with $\mathrm{BC} \leq 30$ years of age with no family history of breast or ovarian cancer and 38 women diagnosed with $\mathrm{BC} \leq 40$ years with one or more first- or second-degree relatives with breast or ovarian cancer. One rare deleterious variant (c.499-500delCA) 
in TP53 was identified in a 28 -year-old BC patient with a negative family history [35].

In Canada, 6 (21.4\%) out of 28 women with early-onset $\mathrm{BC}$ (diagnosed $<30$ years) and a positive family history of cancer were found to carry pathogenic TP53 variantsc. $708 \mathrm{C}>\mathrm{A}$, IVS03-11C $>$ G, c. $524 \mathrm{G}>\mathrm{A}$, c. $818 \mathrm{G}>\mathrm{A}$, c. $743 \mathrm{G}>\mathrm{A})$. Five from the six mutation-positive patients (83\%) met Chompret criteria, and one $(7.7 \%)$ did not meet any current criteria for LFS. They have previously tested negative for mutations in BRCA1/2 genes [36].

In the United States, three variants (p.G245S, p.C277stop, p.R175H) in TP53 were detected among $3 / 300(1 \%)$ breast cancer patients (regardless of age) with positive family history. They came from any region in the United States and self-defined ancestry. All detected pathogenic variants were associated with LFS/LFL syndrome. One of the variants in this study was identified in the current study (p.G245S) [7].

From an Australian population-based series of invasive BC, that included, (a) very early-onset BC cases: 52 women diagnosed under the age of 30 years, unselected for family history and; (b) early-onset disease, 42 women diagnosed under the age of 39 years with positive family history breast or ovarian cancer. In the first subgroup, 2 pathogenic TP53 variants were identified (4\%)—G13203A, 7568-12905del. Neither had a family cancer history that met the criteria for Li-Fraumeni syndrome. In the second subgroup of 42 patients, $3(7 \%)$ carried a pathogenic variant (T13240G, G12299A, 14058delG) in TP53. The recommendation from this report was that women with early-onset BC who had a family history consistent with LFS have a high probability of carrying a germline TP53 pathogenic variant and that subgroups of families with early-onset BC might warrant TP53 screening irrespective of meeting the Chompret and LFS criteria [14].

Bougeard et al. [37] detected TP53 mutations (c.286_288del, c.991C > T, c.375G > A) in 3/45 (6.7\%) women who were diagnosed with breast cancer under 33 years of age with negative family history.

In a Dutch family study, 180 patients were referred for TP53 pathogenic variant screening and were evaluated. Probands were diagnosed with breast cancer $<30$ years of age. A TP53 germline variant was identified in 24 probands who had positive family histories of cancer: 18 variants were found in LFS and LFL families, 2 variants were detected outside the 'Chompret group' - child with rhabdomyosarcoma and a young woman with breast cancer. This study also revealed that among the families of TP53 pathogenic variant carriers in addition to typical LFS tumors, colorectal cancer and pancreatic cancer occurred more frequently than in the general Dutch population [38].

Similar to many other studies, the women carrying germline TP53 pathogenic variants were diagnosed with HER2 positive tumours, three of which were scored at $3+$ and one of them was judged as HER2 negative tumor (HER2 1+).

One Asian study showed that $5 / 83(6 \%)$ of BC patients ( $<35$ years old) carried germline pathogenic variants in TP53. The patients originatted from the three ethnic populations in Malaysia and included Malay, Chinese and Indian women. Variants were only detected among LFS/LFL families and six of the seven breast tumors $(86 \%)$ in these women were associated with amplification of HER2. This suggests that HER2 positive receptor status may be a useful marker to identifying germline pathogen variants in TP53 [8].

Eccles et al. [39] also classified patients for TP53 screening taking into consideration HER2 status (score $3+$ ) from a large UK cohort study. Using this approach, 3\% (9/304) of women were diagnosed with HER2-amplified $\mathrm{BC} \leq 40$ years of age. From 71 BC patients diagnosed under 31 years of age, five carried a pathogenic TP53 variant and none had a history of LFS. While in a cohort of women with HER $2+$ BC diagnosed $\leq 50$ years without any known family history, fulfilling the Chompret criteria, only $1 / 195$ women carried a TP53 pathogenic variant. The authors concluded that patients under 41 years of age with a HER2(+) BC with a negative family history of breast cancer can be reassured that they have a low probability of being a high-risk gene carrier. If, however, there is a strong family history, not only BRCA1 and BRCA2 but also TP53 testing should be considered.

Among our mutation carriers, 3 out of 4 patients (75\%) had HER2 $(3+)$ receptor expression, while among the cohort of $100 \mathrm{BC}$ patients, 21 had a positive HER2 $(3+)$ status. These findings support the results from other studies, which show that in women diagnosed with HER2 positive breast cancer under the age of 30 years with a family history of LFS, indicating that HER2 amplification may be a useful marker in identifying TP53 mutation carriers. Thus we estimate that in Polish population, TP53 mutations can be found around $14 \%$ of HER 2 positive BC diagnosed $\leq 31$ years of age with a positive family history of LFS.

In conclusion, the prevalence of germline pathogenic TP53 variants in early-onset breast cancer in Polish population appears not to be different from those in other populations. Given the 4\% prevalence of the TP53 mutations among Polish patients, we suggest that all patients who develop $B R C A$-negative breast cancer $\leq 30$ years and have a positive family history of LFS-related cancers should be screened for TP53 variants. In addition, patients with HER2 receptor positive tumours should be offered genetic counseling and genetic testing for mutations in TP53 gene. Knowledge about the prevalence of germline pathogenic variants in TP53 coupled with screening for these in appropriately selected women could be beneficial for patients and their families by initiating specific surveillance and treatment options for early cancer detection and/or prevention. 
Acknowledgements The study was approved by the Ethics Committee of the Pomeranian Medical University in Szczecin. Patient clinical data have been obtained in a manner conforming with the IRB ethical guidelines.

\section{Compliance with ethical standards}

Conflict of interest All authors declare no conflict of interest.

Ethical approval All procedures performed in studies involving human participants were in accordance with the ethical standards of the institutional research committee and with the 1964 Helsinki Declaration and its later amendments. The study was approved by the Ethics Committee of the Pomeranian Medical University in Szczecin.

Informed consent Informed consent was obtained from all individual participants included in the study.

Open Access This article is licensed under a Creative Commons Attribution 4.0 International License, which permits use, sharing, adaptation, distribution and reproduction in any medium or format, as long as you give appropriate credit to the original author(s) and the source, provide a link to the Creative Commons licence, and indicate if changes were made. The images or other third party material in this article are included in the article's Creative Commons licence, unless indicated otherwise in a credit line to the material. If material is not included in the article's Creative Commons licence and your intended use is not permitted by statutory regulation or exceeds the permitted use, you will need to obtain permission directly from the copyright holder. To view a copy of this licence, visit http://creativecommons.org/licenses/by/4.0/.

\section{References}

1. World Health Organization. [https://www.who.int/cancer/preve ntion/diagnosis-screening/breastcancer/en/]. Accessed 1 Dec 2019

2. National Cancer Registry, Department of Epidemiology and Cancer Prevention, National Oncology Institute Maria SkłodowskaCurie - National Research Institute. [https://onkologia.org.pl/]. Accessed 1 Dec 2019.

3. Maxwell KN, Wubbenhorst B, D’Andrea K, et al. Prevalence of mutations in a panel of breast cancer susceptibility genes in BRCA1/2-negative patients with early-onset breast cancer. Genet Med. 2015;17(8):630-8.

4. Churpek JE, Walsh T, Zheng Y, et al. Inherited predisposition to breast cancer among African American women. Breast Cancer Res Treat. 2015;149(1):31-9.

5. Palmero EI, Achatz MI, Ashton-Prolla P, et al. Tumor protein 53 mutations and inherited cancer: beyond Li-Fraumeni syndrome. Curr Opin Oncol. 2010;22(1):64-9.

6. Janavičius R, Andrèkute K, Mickys U, et al. Apparently "BRCArelated" breast and ovarian cancer patient with germline TP53 mutation. Breast J. 2011;17(4):409-15.

7. Walsh T, Casadei S, Coats KH, et al. Spectrum of mutations in BRCA1, BRCA2, CHEK2, and TP53 in families at high risk of breast cancer. JAMA. 2006;295(12):1379-88.

8. Lee DSC, Yoon SY, Looi LM, et al. Comparable frequency of BRCA1, BRCA2 and TP53 germline mutations in a multi-ethnic Asian cohort suggests TP53 screening should be offered together with BRCA1/2 screening to early-onset breast cancer patients. Breast Cancer Res. 2012;14(2):R66.
9. Gonzalez KD, Buzin $\mathrm{CH}$, Noltner KA. High frequency of de novo mutations in Li-Fraumeni syndrome. J Med Genet. 2010;46(10):689-93.

10. Kratz CP, Achatz MI, Brugières L, Frebourg T, et al. Cancer screening recommendations for individuals with Li-Fraumeni syndrome. Clin Cancer Res. 2017;23(11):e38-e45.

11. Fortuno C, James PA, Spurdle AB. Current review of TP53 pathogenic germline variants in breast cancer patients outside Li-Fraumeni syndrome. Hum Mutat. 2018;39(12):1764-73.

12. Mouchawar J, Korch C, Byers T, et al. Population-based estimate of the contribution of TP53 mutations to subgroups of early-onset breast cancer: Australian Breast Cancer Family Study. Cancer Res. 2010;70(12):4795-800.

13. Fostira F, Konstantopoulou I, Mavroudis D, Tryfonopoulos D, et al. Genetic evaluation based on family history and Her2 status correctly identifies TP53 mutations in very early onset breast cancer cases. Clin Genet. 2015;87(4):383-7.

14. Olivier M, Hollstein M, Hainaut P. TP53 mutations in human cancers: origins, consequences, and clinical use. Cold Spring Harb Perspect Biol. 2010;2(1):a001008.

15. Silwal-Pandit L, Langerød A, Børresen-Dale A-L. TP53 mutations in breast and ovarian cancer. Cold Spring Harb Perspect Med. 2017;7(1):a026252.

16. Huszno J, Grzybowska E. TP53 mutations and SNPs as prognostic and predictive factors in patients with breast cancer. Oncol Lett. 2018;16(1):34-40.

17. International Agency for Research on Cancer, Lyon, France (2019). [https://p53.iarc.fr/]. Accessed 10 Dec 2019.

18. Smith MJ, Urquhart JE, Harkness EF. The contribution of whole gene deletions and large rearrangements to the mutation spectrum in inherited tumor predisposing syndromes. Hum Mutat. 2016;37(3):250-6.

19. Bougeard G, Renaux-Petel M, Flaman J-M, et al. Revisiting LiFraumeni syndrome from TP53 mutation carriers. J Clin Oncol. 2015;33(21):2345-52.

20. Mai PL, Malkin D, Garber JE, et al. Li-Fraumeni syndrome: report of a clinical research workshop and creation of a research consortium. Cancer Genet. 2012;205(10):479-87.

21. MutationTaster. [https://www.mutationtaster.org/]. Accessed 20 Nov 2019.

22. ClinVar [https://www.ncbi.nlm.nih.gov/clinvar/]. Accessed 20 Nov 2019.

23. Protein Variation Effect Analyzer. [https://provean.jcvi.org/ seq_submit.php]. Accessed 20 Nov 2019.

24. Polymorphism Phenotyping v2. [https://genetics.bwh.harva rd.edu/pph2/]. Accessed 20 Nov 2019.

25. Align-GVGD. [https://agvgd.hci.utah.edu]. Accessed 20 Nov 2019.

26. Arcand SL, Akbari MR, Mes-Masson AM, et al. Germline TP53 mutational spectrum in French Canadians with breast cancer. BMC Med Genet. 2015;16:24.

27. The Genome Aggregation Database (gnomAD) (2019). [https ://gnomad.broadinstitute.org/variant/]. Accessed 11 Dec 2019.

28. Zhang Y, Coillie SV, Fang J-Y. Gain of function of mutant p53: R282W on the peak? Oncogenesis. 2016;5(2):e196.

29. Olfson E, Cottrell CE, Davidson NO, et al. Identification of medically actionable secondary findings in the 1000 genomes. PLoS ONE. 2015;10(9):e0135193.

30. Lin P-H, Kuo W-H, Huang A-C. Multiple gene sequencing for risk assessment in patients with early-onset or familial breast cancer. Oncotarget. 2016;7(7):8310-20.

31. Park JS, Lee ST, Nam EJ. Variants of cancer susceptibility genes in Korean BRCA1/2 mutation-negative patients with high risk for hereditary breast cancer. BMC Cancer. 2018;18:83.

32. Nordfors K, Haapasalo J, Afyounian E, et al. Whole-exome sequencing identifies germline mutation in TP53 and ATRX 
in a child with genomically aberrant AT/RT and her mother with anaplastic astrocytoma. Cold Spring Harb Mol Case Stud. 2018;4(2):a002246.

33. Bakhuizen JJ, Hogervorst FB, Velthuizen ME, et al. TP53 germline mutation testing in early-onset breast cancer: findings from a nationwide cohort. Fam Cancer. 2019;18(2):273-80.

34. Gallardo-Alvarado LN, Tusié-Luna MT, Tussié-Luna MI, et al. Prevalence of germline mutations in the TP53 gene in patients with early-onset breast cancer in the Mexican population. BMC Cancer. 2019;19:118.

35. Rashid MU, Gull S, Asghar K, Muhammad N, et al. Prevalence of TP53 germ line mutations in young Pakistani breast cancer patients. Fam Cancer. 2012;11(2):307-11.

36. McCuaig JM, Armel SR, Novokmet A, et al. Routine TP53 testing for breast cancer under age 30: ready for prime time? Fam Cancer. 2012;11(4):607-13.
37. Bougeard G, Sesboüé R, Baert-Desurmont S, et al. Molecular basis of the Li-Fraumeni syndrome: an update from the French LFS families. J Med Genet. 2008;45(8):535-8.

38. Ruijs MW, Verhoef S, Rookus MA, et al. TP53 germline mutation testing in 180 families suspected of Li-Fraumeni syndrome: mutation detection rate and relative frequency of cancers in different familial phenotypes. J Med Genet. 2010;47(6):421-8.

39. Eccles DM, Li N, Handwerker R, et al. Genetic testing in a cohort of young patients with HER2-amplified breast cancer. Ann Oncol. 2016;27(3):467-73.

Publisher's Note Springer Nature remains neutral with regard to jurisdictional claims in published maps and institutional affiliations. 